\title{
A transição paradigmática da saúde como um dever do cidadão: um olhar da bióétice em Saúde Pública
}

Paula Gaudenzi ${ }^{1}$

Fermin Roland Schramm²

GAUDENZI, P.; SCHRAMM, F.R. The paradigmatic transition of healthcare as a citizen's duty: a look at bioethics in public health. Interface - Comunic., Saude, Educ., v.14, n.33, p.243-55, abr./jun. 2010.

One of the current concerns within public health relates to the type of responsibility that could legitimately be demanded from individuals regarding their health. In particular, it is asked whether some form of penalization against behavior that is not considered healthful can be morally justified. Bioethics applied to the morality of public health actions has the aims of both ensuring the access standards to a healthcare system with universal coverage and developing human capacities. It therefore has to face the conflict between the principles of social justice and individual autonomy, weighing up protection of health for those who need this, versus the basic freedoms of each and every one. For this, bioethics and public health will have to interrogate the biopolitical effects inscribed in sanitary policies, situated at the crossroads between the Age of Rights and the State of Exception.

Keywords: Bioethics. Public health. Autonomy. Biopolitics. Health promotion.
Uma das preocupações atuais da saúde pública é qual seria o tipo de responsabilização que poderia legitimamente ser exigida dos indivíduos pela sua saúde e, em particular, perguntar-se se é moralmente justificada alguma forma de penalização contra os comportamentos considerados não saudáveis. A bioética aplicada à moralidade das ações em saúde pública pretende garantir tanto um padrão de acesso a um sistema de saúde com cobertura universal quanto o desenvolvimento das capacidades humanas, devendo, portanto, enfrentar o conflito entre os princípios da justiça social e da autonomia individual, ponderando a proteção da saúde dos necessitados e as liberdades fundamentais de todos e de cada um. Para isso, bioética e saúde pública deverão interrogar-se sobre os efeitos biopolíticos inscritos nas políticas sanitárias, situando-se na encruzilhada entre a Era dos Direitos e o Estado de Exceção.

Palavras-chave: Bioética. Saúde pública. Autonomia. Biopolítica. Promoção da saúde. (1) 


\section{Introdução}

No campo da Saúde Pública o impasse entre justiça social e autonomia individual pode surgir quando se pretende que a alocação equitativa de recursos seja, ao mesmo tempo, igualitária e libertária, pois, neste caso, podem aparecer, no cômputo, fatores discriminantes supostamente pertinentes, mas que podem ser questionados em algum aspecto importante. Por exemplo, uma das grandes preocupações atuais da Saúde Pública diz respeito ao tipo de controle de comportamentos daqueles que possuem estilos de vida considerados não saudáveis (Fortes, Zoboli, 2003), o que nos leva à discussão sobre qual seria o tipo de responsabilização legítima do indivíduo pela própria saúde. Mas abordar a responsabilidade de alguém por sua saúde implica perguntar-se se é moralmente justificado considerar que isso resultará em alguma forma de penalização contra os comportamentos considerados não saudáveis que este alguém possa ter, mesmo quando tais comportamentos não prejudiquem, de forma significativa, terceiros. De fato, a moralidade de um comportamento implica sempre, como condição necessária, uma estrutura composta por, pelo menos, dois sujeitos: um agente moral - autor do ato a ser considerado - e um paciente moral - destinatário deste ato. Sendo assim, não se pode, a rigor, falar em moralidade quando o ato de um indivíduo não prejudicar, de maneira significativa, outro(s) indivíduo(s) ou grupo(s) de indivíduos, chamado(s) população (Schramm, 2006), pois, neste caso, agente moral e paciente moral coincidem.

Entretanto, existe atualmente uma tendência a ampliar a responsabilização individual no âmbito sanitário, deixando de se restringir às consequências que o comportamento de um indivíduo possa ter sobre terceiros, e incluindo também as eventuais consequências sobre a saúde do próprio agente moral, não distinto do destinatário. Neste caso, o argumento utilizado para justificar esta autorresponsabilização refere-se quase sempre ao problema dos recursos finitos e escassos, problema que se tornou uma espécie de constante universal da bioética sanitária. Para Dernier (2005), por exemplo, uma das razões aduzidas para responsabilizar alguém pela sua saúde é o problema dos custos cada vez maiores na área; e, neste sentido, argumenta-se que os indivíduos teriam, sim, uma responsabilidade moral pela sua saúde, uma vez que, ao colocá-la em risco, estariam fazendo um uso indevido dos recursos escassos que são da coletividade, e, portanto, que tais indivíduos deveriam sofrer penalidades por não permanecerem saudáveis, podendo perder a prioridade no caso de precisarem de um tratamento (Wikler, 2002), como, por exemplo, o transplante de um órgão afetado pelo comportamento moralmente questionável do paciente.

Tal discussão tem grande relevância bioética, pois o que está em jogo - por trás desta responsabilização frente aos recursos finitos e escassos - é a tensão entre dois princípios morais: o da justiça social e o da autonomia individual, considerados no contexto de uma "topologia administrativa" consistente em procedimentos que se destinam, em última instância, a finalizar a conduta humana de acordo com um paradigma econômico que controle o comportamento dos humanos e tenha em vista o difícil equacionamento entre competição e cooperação (Cillo, 2006).

Considerando tanto a saúde como o exercício das liberdades, condições igualmente necessárias para se garantir a qualidade de vida, pode-se dizer que a bioética se ocupa com a proteção num duplo sentido, pois pretende garantir o acesso a um padrão de assistência em saúde razoável para todos e que seja congruente com o desenvolvimento das capacidades humanas, entendido como expansão das liberdades pessoais (Sen, 2000). Assim, proteger a saúde de todos não pode implicar, sem mais, a não proteção das liberdades fundamentais de cada um. A bioética se insere nesta discussão com o intuito de compreender e analisar criticamente o conflito para, então, fornecer bons argumentos para poder proscrever ou prescrever atitudes com legitimidade, estabelecendo pontos de convergência entre o valor justiça social e o valor liberdades fundamentais individuais. Mas, para isso, tanto a bioética como a Saúde Pública não podem esquecer os efeitos biopolíticos e de biopoder inscritos nas políticas sanitárias, quando estas implicam o controle de comportamentos individuais supostamente em prol do interesse coletivo. 


\section{Possíveis implicações biopolíticas das políticas sanitárias}

Foucault, em meados dos anos 70, referiu-se a uma nova técnica de poder chamada biopoder, não mais dirigida apenas ao corpo individual por meio da tecnologia disciplinar, mas também ao conjunto de viventes chamado de população. Enquanto nos séculos XVII e XVIII havia um poder que deveria se exercer da maneira menos onerosa possível fazendo do corpo o alvo de técnicas que tentavam aumentar-lhe a força útil, na segunda metade do século XVIII surge um novo olhar que se concretiza numa biopolítica, com novos objetos: a população como um todo e o homem vivo considerado como espécie. A biopolítica é, portanto, uma prática dos governos que se destina a garantir e incentivar a saúde coletiva pelo controle da natalidade, fecundidade e mortalidade; o controle das enfermidades endêmicas e epidêmicas, e o controle dos eventos e fenômenos que incidem sobre a segurança e o funcionamento das sociedades (Foucault, 2005, 1997).

Algumas práticas biopolíticas se colocam como problemas morais que devem ser analisados. Primeiramente, a biopolítica considera que as necessidades são as mesmas para todos, sendo estas limitadas à esfera biológica e, portanto, desconsideram-se as diferenças fundamentais que permitem a cada humano ser-uma singularidade entre outras singularidades. Outro problema é que, uma vez que as políticas públicas da biopolítica são entendidas como necessárias, a busca compulsória pela saúde passa a ser vista como politicamente e eticamente correta, criando, assim, uma ideologia que alguns autores denominam de healthism (Ortega, 2003). Pessoas saudáveis se tornam modelos a serem seguidos e a saúde passa a ter a qualidade de um fim em si (Crawford, 1980), fazendo com que a negligência com a saúde própria se torne imoral, e o comportamento saudável o paradigma de uma vida boa, inclusive sob o aspecto moral.

Ainda neste sentido, ao se expandir o ideal de prevenção, que considera praticamente tudo como fator de risco e todas as pessoas como potencialmente indivíduos em risco, novas obrigações consigo e com os outros são exigidas. Mas, neste caso, o grande problema - ao mesmo tempo epistemológico e ético - é que não se faz a distinção entre tipos de riscos; entre agentes e pacientes de riscos; entre os riscos que podem ser administrados com as biotecnologias e outros riscos referentes a indivíduos ou grupos que têm certos hábitos considerados incorretos por uns mas não por outros, como se tais hábitos tivessem uma mesma dimensão moral, independente do fato de o indivíduo colocar em risco sua própria saúde, e não a saúde de outrem. Em outros termos, a biopolítica pode, com base nesta reflexão, ser vista como uma nova forma de discriminação daqueles indivíduos com hábitos considerados prejudiciais à saúde pessoal, podendo tornar-se liberticida em nome de uma suposta garantia da saúde coletiva (Schramm, 2006).

A saúde pública age, muitas vezes, limitando, com boas razões, as liberdades individuais, como é o caso do interesse público; em ações como a vigilância epidemiológica, a vigilância sanitária, o controle de zoonoses e a saúde do trabalhador (Fortes, Zoboli, 2003). É certamente razoável acreditar que, em muitas situações em que está em jogo algo como um bem comum, o interesse coletivo possa ter prioridade sobre o interesse individual. Nas situações de epidemias, por exemplo, a rígida restrição das liberdades individuais pode ser legítima, valendo o "princípio da proteção do 'corpo social' contra as ameaças de indivíduos e grupos que possam prejudicá-lo" (Schramm, 2003, p.83). Mas o que parece estar se instaurando atualmente é um dispositivo biopolítico de controle que extrapola o nível razoável de proteção dos legítimos interesses da coletividade, agindo sobre comportamentos e condutas humanas que, de fato, dizem respeito ao nível privado, sem que haja qualquer justificativa razoável para subsumir este àquele.

Com outras palavras, o que acontece é uma subsunção dos direitos pessoais aos direitos coletivos, tendo como justificativa uma não melhor definida necessidade coletiva, independente das circunstâncias e da complexidade social inerente às democracias pluralistas contemporâneas. No caso da saúde, esta necessidade é devida à questão espinhosa da escassez de recursos. Com efeito, o problema dos custos cada vez mais altos em saúde - por gerar um conflito (ou supostamente tal) entre os princípios da autonomia individual e da justiça social - está levando à discussão sobre a extensão do direito à saúde, o qual foi qualificado como um direito humano fundamental na Constituição da 
República Federativa do Brasil de 1988, mas que parece transformar-se, atualmente, em algo como um dever individual, pois os indivíduos são instados a serem saudáveis em uma situação caracterizada como a de recursos finitos e escassos, inscritos, portanto, naquela que o bioeticista Daniel Callahan (1987) definiu como "cultura dos limites".

A "cultura dos limites" é certamente uma postura razoável quando considerarmos, simultaneamente, a transição epidemiológica, as crescentes necessidades de saúde e a "hipercrise sanitária" das sociedades contemporâneas (Schramm, 1996). Entretanto, existem também boas razões para se pensar a "cultura dos limites" em termos autorreferenciais, isto é, pensar os limites da própria cultura dos limites, sobretudo tendo em conta a implementação progressiva de medidas coercitivas excepcionais generalizadas e que Agamben (2004) definiu como "estado de exceção" permanente, baseado em supostas verdades epistêmicas que teriam a capacidade de dar um fundamento normativo para o exercício do biopoder. Com efeito, é próprio do Estado de Exceção a suspensão parcial ou total do ordenamento jurídico, representando, assim, uma espécie de totalitarismo moderno em que categorias inteiras de cidadãos têm suspensas suas liberdades individuais, por serem supostamente não integráveis ao sistema político. Ocorre que o Estado de Exceção na política contemporânea fundamentado no conceito de necessidade - tende a se apresentar como paradigma dominante de governo. Porém, tal conceito de necessidade é opinável nas democracias pluralistas contemporâneas quando não estabelecido consensualmente, o que, no campo da saúde, está levando a responsabilizar o indivíduo pela sua saúde, restringindo o campo de suas liberdades, ou "capacidades" (Sen, 2000) em como levar a vida, em nome de uma suposta necessidade que implicaria per se tal restrição. Em suma, há uma "biopolítica global baseada numa suposta necessidade de comportamentos individuais considerados saudáveis de acordo com o 'paradigma' dominante do momento, mas que, de fato, é um modelo construído sobre uma confusão entre dados de um evento e probabilidades de um evento, e entre potencialidade e atualização" (Schramm, 2006, p.196).

No início do século XXI, o Estado, que até então tinha a responsabilidade de reduzir as desigualdades de renda e melhorar as condições de higiene da população, se torna um coadjuvante neste processo à medida que a responsabilidade pelo cuidado com a saúde cabe a cada indivíduo que, diante das informações médicas, deve ser capaz de mudar seus hábitos de vida (Vaz, Bruno, 2002). A saúde e a doença passam, portanto, a ser compreendidas como resultado do comportamento, e não mais como efeitos das condições de vida; e o indivíduo - agora supostamente informado - passa a ser o único responsável pelo cuidado com sua saúde, cabendo ao Estado o controle para que esta responsabilização seja efetiva. A "verdade" sobre as necessidades para uma vida saudável é posta e os indivíduos - entendidos como seres racionais e razoáveis - deveriam, de forma inteligente, seguila e obedecer às eventuais injunções resultantes da caracterização de comportamentos julgados corretos ou incorretos e a serem seguidos ou evitados, obrigatoriamente. Mas, neste contexto, o Estado pode sentir-se destituído da responsabilidade pela saúde daquele que mantinha um estilo de vida considerado não saudável e adoeceu, pois com base em supostas verdades epistêmicas sobre causas e efeitos do adoecimento - que de fato são meros indícios estatísticos - produz e divulga os conhecimentos sobre como cuidar da saúde, determinando os comportamentos dos sãos e retirando o direito de cada um de escolher o próprio estilo de vida.

Esta preocupação se mostra bastante presente na medicina preventiva do século XX que, assim como a Higiene do século XIX, utiliza-se da autoridade da ciência para produzir um discurso sobre o que se deve e o que não se deve fazer em termos de saúde, criando, assim, um julgamento moral sobre o comportamento humano, mesmo quando este não tenha efeitos significativos sobre terceiros. A "medicina promotora" (Arouca, 2003) - variante da medicina preventiva -, ao atuar por meio da difusão dos conhecimentos científicos, abriu espaço para a imposição de uma versão de conhecimento que implica efeitos pragmáticos, como determinados comportamentos a serem necessariamente adotados, ou relações biopolíticas e de biopoder específicas que se destinariam a proteger o interesse coletivo contra os comportamentos de risco individuais. Em suma, essa produção e difusão da ciência "se estabelece como a suprema autoridade sobre o que é bom ou mal para a saúde de cada um e para a própria existência humana, fazendo da noção do risco em saúde o epicentro em torno do qual gravitam as normas de conduta que prescreve" (Arouca, 2003, p.178). 


\section{Risco em saúde}

Uma das questões centrais em saúde diz respeito aos assim chamados riscos. Como afirma Caliman, na análise foucaultiana sobre o biopoder na racionalidade de governo moderna, colocase a ideia de que a sociedade deve ser defendida de seu perigo interno e "o indivíduo [deve] ser o 'autor ativo' de suas escolhas de vida, e, também, o único responsável pelos riscos e perigos que estas escolhas implicam" (Caliman, 2001, p.92).

Por isso, as condutas entendidas como moralmente responsáveis são apresentadas como opostas aos comportamentos de risco, e o ato de não se precaver é visto como negativo socialmente (Vaz, 2004), fazendo com que aquele indivíduo que não cuida da própria saúde seja considerado como alguém que falhou em seu comportamento, considerado "de risco" e tendo, assim, que responder por seu "erro". Portanto, a saúde passa a ser entendida como uma obrigação do próprio cidadão consigo mesmo e com os outros, ou seja, "a saúde não é mais, em última instância, um direito do cidadão e um dever do Estado, mas, ao contrário, um dever do cidadão e um direito do Estado" (Schramm, 2006, p.196).

Apesar de não se poder contestar o fato de a saúde ser um direito dos cidadãos no Brasil, pois o mesmo é garantido na Constituição do país e, portanto, trata-se de uma responsabilidade jurídica do Estado, ela pode ser metaforicamente interpretada como um direito do Estado quando este faz uso de discursos científicos para propor formas de vida ideais e que, na realidade, refere-se a uma preocupação estritamente econômica relacionada com os custos em saúde. A crítica que fazemos neste sentido referese, de um lado, à criação de indivíduos socialmente responsáveis por questões estritamente privadas e que, portanto, não deveriam ter caráter moral e, por outro, a uma possível futura desresponsabilização - de fato constitucional - do Estado. Acredita-se, diferentemente, na necessidade de uma ética da responsabilidade pública (Jonas, 2006), em que o Estado responsável garanta aos cidadãos a liberdade que lhes é fundamental para se constituírem como sujeitos ativos e para participarem das decisões políticas, ao mesmo tempo em que garanta a justiça social, não podendo assim se confundir com um Estado paternalista. Da mesma forma, em relação ao dever com o cuidado com a saúde não nos referimos à responsabilidade jurídica, mas à responsabilidade moral dos indivíduos do século XXI, que se situam em uma perspectiva cada vez mais individual e que - sem referências coletivas, institucionais ou familiares - transferem a luta por mudanças nas condições sociais, políticas e econômicas da sociedade para uma luta de autoaperfeiçoamento vazia de dimensão política.

Berlinguer (2004), em seu livro "Bioética Cotidiana", retoma uma objeção de Allegrante e Sloan que, ao falarem sobre Promoção de Saúde, afirmam que os indivíduos - em vez da organização social - estão sendo encarregados desta prática, já que eles são vistos como a causa das suas doenças. O que está em questão aqui é a percepção de um mundo equânime, no qual "as pessoas obtêm aquilo que merecem e merecem aquilo que obtêm" (Berlinguer, 2004, p.140). Uma possível consequência desta tendência seria a "responsabilização da vítima" (victim blaming) (Crawford, 1997), fazendo com que o foco do problema seja o indivíduo, e não o problema em si, suas causas e implicações. Outra seria a imposição de comportamentos pessoais considerados saudáveis, o que se apresenta como uma "excelente" solução por ser menos custosa e menos comprometedora para os órgãos públicos do que uma mudança estrutural que possibilitasse que os indivíduos saíssem de suas condições de sujeitos "vulnerados".

A seguir, por meio da análise das Declarações de Saúde que se sucederam desde Alma-Ata, pretendemos mostrar que a crescente importância da saúde na sociedade contemporânea e a grande ênfase dada aos estilos de vida (Herzlich, 2004) têm levado à transferência de responsabilidade pela saúde do domínio público para o privado.

\section{As Declarações de Saúde que sucederam à Conferência de Alma Ata}

A incorporação da idéia de Promoção de Saúde e de sua prática no campo da Saúde Pública foram influenciadas especialmente pela reforma da saúde do Canadá em 1974 (Souza, Grundy, 2004), com a divulgação do Relatório Lalonde (Lalonde, 1974). A reforma destinava-se a enfrentar os custos cada vez maiores da assistência médica devido à incorporação de alta tecnologia, mas, também, se insere em um contexto em que a abordagem exclusivamente médica para as doenças crônicas 
estava sendo severamente criticada (Buss, 2000). No Relatório, o conceito de campo de saúde inclui não mais apenas os serviços de saúde, mas todas as práticas e os saberes que influenciam a saúde (Carvalho, 2004), sendo composto por quatro polos: a biologia humana; o sistema de organização dos serviços; o ambiente e o estilo de vida (Paim, Almeida, 1998). Este último aspecto se refere à ênfase na moderação de comportamentos de risco e é trabalhado, neste artigo, por meio da revisão das declarações de saúde.

\section{Declaração de Alma Ata}

A primeira Conferência Internacional sobre Cuidados Primários de Saúde, organizada pela Organização Mundial de Saúde (OMS) e pelo Fundo das Nações Unidas para a Infância (UNICEF), foi realizada em 1978 e resultou na Declaração de Alma-Ata (1978). Nesta reafirmou-se o significado da saúde como um direito humano fundamental, sendo a consecução do mais alto nível possível de saúde a mais importante meta social mundial, sob responsabilidade política dos governos.

Apesar da referência à responsabilidade dos governos para com a saúde de seus povos, a Declaração afirmara, no parágrafo IV, que "é direito e dever dos povos participar individual e coletivamente no planejamento e na execução de seus cuidados de saúde", o que coloca uma dupla questão: (a) qual o tipo de relação que se pretende estabelecer entre "direitos" e "deveres"; (b) qual a abrangência deste dever e como ele deveria ser cumprido individualmente. Uma outra reflexão que parece necessária é sobre qual seria a pretensão do movimento de Promoção de Saúde: a beneficência dos destinatários (ou tentativa de contribuir para o bem-estar do indivíduo) ou uma suposta justiça sanitária consistente em uma melhor saúde para todos, mais para reduzir os custos do que para melhorar a qualidade de vida de todos?

Neste sentido há, por um lado, o objetivo de fortalecer os indivíduos em suas capacidades e utilizar a Promoção de Saúde como estratégia para criar mudanças na relação entre os cidadãos e o Estado, constituindo-se numa perspectiva libertária que busca mudanças sociais mais profundas - como são as propostas de educação popular (Castiel, 2004) - e, por outro, a intenção de conduzir indivíduos a assumirem a responsabilidade por sua saúde e, ao assim fazerem, reduzir o peso financeiro na assistência à saúde. Mas isso pode ter como resultado "grupos de indivíduos entregues a si próprios e à preocupação com o desempenho baseado em condições individuais quanto a recursos e capacidade de incorporar semimitos que sustentem uma identidade frágil, povoada cada vez mais por um imaginário composto por elementos vinculados a 'questões de saúde'" (Castiel, 2003, p.92) - o que merece uma discussão ética.

\section{A nova promoção à Saúde}

Em meados da década de 1980, a fim de superar o projeto behaviorista da Promoção da Saúde - que preconiza como eixo central de intervenção um conjunto de ações que procurassem intervir positivamente sobre comportamentos individuais não saudáveis e que desconsiderassem as estruturas sociais causadoras da falta de saúde -, formulou-se a vertente socioambiental denominada Nova Promoção à Saúde (Carvalho, 2004), que passa então a ser entendida como um processo de capacitação de indivíduos e coletividades para controlarem os determinantes da saúde, combinando escolhas pessoais com responsabilidade social. O novo ideário proposto visa mudanças nas condições e no modo de vida das pessoas, o que, a princípio, poderia trazer bons resultados, mas que, em nossa compreensão, tem levado a uma restrição das liberdades individuais, ao impor comportamentos considerados saudáveis, de acordo com o modelo oikonômico neoliberal e em nome de uma suposta garantia da saúde e do bem-estar do corpo social (Schramm, 2006) sem que haja qualquer justificativa razoável para tal.

Em 1986, a Conferência de Ottawa sintetizou esta produção e deu origem ao primeiro documento internacional em Promoção de Saúde - a Carta de Ottawa (1986) - que afirma: "as ações de promoção da saúde [...] [devem] capacitar todas as pessoas a realizar completamente seu potencial de saúde" (Carta, 1986, p.2). Mas, se considerarmos - como diz a Carta - que as pessoas devam ser 
capazes de escolher uma vida mais sadia, temos também que levar em conta as diferenças subjetivas de apreciação; caso contrário, arrisca-se abrir brechas para a perversão da norma e a possibilidade de surgirem novos conflitos entre direitos individuais e direitos coletivos.

Com efeito, a ideia de que o indivíduo deve ser capaz de controlar os fatores determinantes de sua saúde pode levar, além da subsunção da complexidade social ao modelo oikonômico da produção industrial - que pode ser criticado porque implica uma redução do papel protetor do Estado -, ao julgamento moralista do indivíduo como culpado por sua condição e, portanto, merecedor de alguma sanção. Pode acontecer com os obesos que, considerados desleixados e feios, "pagam a pena" de serem pouco amados; com os sedentários, vistos como loosers por não exibirem músculos e por não frequentarem o grande lugar da moda - a academia. A justificativa é óbvia e até aparentemente "razoável", porém criticável, pois não tem em devida conta características singulares, especificidades de situações e outras contingências pertinentes. Talvez este seja o primeiro passo para, depois, velhos, gordos, anoréxicos, sedentários, estressados, fumantes, alcoólatras, praticantes de esportes radicais etc., terem o acesso aos cuidados de saúde restrito, supostamente de forma "justificada". $E$, então, os merecedores de cuidado serão os jovens, esbeltos, não estressados (provavelmente aqueles não escravizados pelo trabalho e em boas condições de vida), os "politicamente corretos" ou "equilibrados" e aqueles de vida "pacata". Estes indivíduos compulsoriamente integrados no tipo ideal da pessoa saudável terão, assim, uma espécie de prioridade moral no acesso aos cuidados, enquanto aqueles já descuidados pela vida, ou "vulnerados" devido a este descuido e, também, aqueles que desejarem uma vida autônoma tenham tal acesso negado. Em contrapartida, o gasto do governo com a saúde será significativamente diminuído e o custo da saúde para os indivíduos será cada vez maior, de um lado, pagando por produtos diets, por academia, ou tranquilizantes, e, por outro, pelo custo da discriminação e do abandono.

Os autores da Carta advertem que "a saúde deve ser vista como um recurso para a vida, e não como objetivo de viver" (Carta, 1986, p.1), ou seja, como meio, e não como fim em si. Porém, devido à discriminação dos "não saudáveis", a adequação a um estilo de vida imposto - embora não desejado - pode se tornar a única saída para os discriminados. Assim, a saúde não seria vista como um recurso (ou meio) para se viver, mas, sim, como um fim a ser alcançado para se poder viver numa sociedade marcada pela intolerância diante das diferenças; em particular, aquelas relativas aos estilos de vida.

Apesar da feliz advertência da Carta para não confundir meios e fins, a própria deixa espaço para o entendimento da busca pela saúde como um dever, ao dizer: "[a]s pessoas, em todas as esferas da vida, devem envolver-se neste processo [de promoção da saúde] como indivíduos, famílias e comunidades" (Carta, 1986, p.2, grifo nosso). Acreditamos que uma das possíveis razões desta ambiguidade seja o fato de a definição de saúde se situar entre dever e direito. Então, a crítica que se torna necessária é que as pessoas não devem necessariamente estar envolvidas com a preservação de sua saúde entendida como um objetivo de suas vidas, podendo a mesma ser compreendida como um de seus meios para alcançar uma qualidade de vida julgada desejável e satisfatória pelos seus titulares. Com efeito, existem boas razões para poder afirmar que o indivíduo, como um ser autônomo e razoável, deve ter a possibilidade de escolher entre ser ou não ser "saudável", de acordo com seu desejo; e deve ter liberdade para identificar o que lhe faz bem e o que lhe faz mal. Assim, tanto a saúde jamais poderia se tornar um dever do indivíduo, como a saúde pública não deveria, neste contexto, dizer o que fazer ou não fazer, mas, sim, prover, além de um padrão de assistência razoável, informação a respeito das questões relacionadas à saúde, deixando ao indivíduo escolher o que diz respeito a sua vida, desde que isso não comprometa realmente terceiros. Existem, evidentemente, situações limites, como aquela dos fumantes e dos assim chamados fumantes passivos, que podem, eventualmente, ter sua saúde prejudicada pelos primeiros. Entretanto, pode-se suspeitar de que, por trás deste argumento razoável, "o que está realmente em questão é que existem outros que, por fumarem, comprazem-se com demasiada intensidade, de uma forma autodestrutiva - e isso é insuportável [pois o] que temos aí, no que há de mais puro, [é] a imagem do vizinho invasivo que goza demais" (Zizek, Daly, 2006, p.92). Em outros termos, o healthism subjacente à Promoção da Saúde pode implicar um paradoxo: "para realmente gozarmos a vida, temos de seguir um sem número de normas e proibições: nada [de] fumo, alimentos gordurosos, álcool, ovos, nada de 
situações estressantes, [sendo que] se você postula o prazer diretamente como uma meta, é obrigado a se submeter a diversas condições [...] de modo que seu prazer imediato torna a se estragar" (Zizek, Daly, 2006, p.143).

As políticas públicas, que tenham como preocupação a saúde da população, devem, de nosso ponto de vista, visar à melhora das condições de vida da população sem limitar ou aniquilar as liberdades individuais injustificadamente, impondo estilos de vida e tornando o cuidado à saúde uma obrigação do indivíduo, de acordo com parâmetros econômicos opináveis. Como diz Carvalho (2004), a prioridade não deveria ser dada aos estilos de vida saudáveis, mas, sim, às condições de vida e trabalho saudáveis. Apesar do entendimento de que as Políticas Públicas Saudáveis tentam contribuir para uma escolha de vida saudável, e não para uma imposição, acreditamos que este discurso colabora para a criação de uma ordem social onde "o valor dos indivíduos reside na apreensão de possibilidades e na habilidade em evitar ou gerir o risco" (Vaz, Bruno, 1999), ordem esta que pode estar equivocadamente inserindo uma dimensão moral (que sempre implica uma relação entre um agente em um paciente moral) em ações que dizem respeito apenas às liberdades individuais. $\mathrm{O}$ discurso da Promoção de Saúde centrado fundamentalmente na gestão dos riscos - e consequente mudança dos comportamentos - se apresenta esvaziado de análise política, pois se sustenta na ideia de que o sofrimento humano deriva de escolhas individuais ou do descontrole de alguns, deixando de identificar as causas básicas e estruturais do mesmo, e gerando indignação daqueles que cuidam de sua saúde em relação àqueles que não o fazem.

Contribuindo para a discussão ética sobre a saúde ser um direito ou um dever do cidadão, os profissionais que trabalham com a Promoção da Saúde deveriam refletir sobre a perversão da norma consistente na resistência aos programas de monitoramento de fatores de risco comportamental, que de fato não são tão bem-sucedidos como as autoridades sanitárias almejam (Castiel, 2004). Neste caso, coloca-se em questão se esta responsabilização do indivíduo por sua saúde não seria algo que exige dos indivíduos mais do que lhes é possível, sobretudo tendo em conta que vivemos em sociedades ditas de risco e que a própria discussão sobre a "sociedade de risco" pode ser vista como uma "ideologia [que interpreta] como nossas opções de risco aquilo que nos é imposto como um destino cego [...] objetivado como uma espécie de fatum anônimo" (Zizek, Daly, 2006, p.135).

\section{Pós-Ottawa}

Aprofundando as discussões sobre os aspectos enunciados na Carta de Ottawa, diversas conferências foram realizadas e reforçaram as mesmas propostas; portanto, ressaltaremos pequenos detalhes que parecem fortalecer a hipótese da transição paradigmática que estamos analisando.

Em 1988, a Declaração de Adelaide, que tratou das Políticas Públicas Saudáveis (Declaração de Adelaide, 1988), afirmara que a população deveria ter acesso aos meios imprescindíveis para uma vida saudável; porém, relacionara o nível de saúde da população com a produtividade da sociedade. Subentendia-se, desta forma, que as pessoas devem ser saudáveis em nome da sociedade, trazendoIhe benefícios econômicos. A saúde individual deixaria de ser de fato individual tornando-se do domínio público e, portanto, passível de sofrer interferências de todos que, supostamente, agirem em prol do bem da sociedade.

A Declaração de Sundsvall, de 1991, envolveu-se com Ambientes Favoráveis à saúde e Desenvolvimento Sustentável em relação à qualidade de vida (Declaração de Sundsvall, 1991). O documento, apesar de defender interesses coletivos, apresenta, em algumas passagens, um caráter ambíguo sobre o papel dos indivíduos neste processo, além de deixar em aberto seus deveres em relação à saúde individual. Ao afirmar que o termo "ambientes saudáveis" alcança todos os espaços em que as pessoas vivem, inclusive suas casas e lazeres, observa-se que este discurso está penetrando também na vida privada das pessoas. Se este pensamento tiver fundamento, devemos então refletir se há razões válidas para que esta intervenção seja aplicada.

A Declaração de Bogotá, de 1992, ocupou-se com a adequação da Promoção da Saúde aos países em desenvolvimento (Declaração de Santafé de Bogotá, 1992). A Declaração não deixa claro qual seria o dever que cada um tem em relação à saúde: a sua ou a de outrem. A Promoção da Saúde 
teria o papel de identificar os fatores que favorecem a inequidade e propor ações que diminuam seus efeitos. De um ponto de vista moral pode-se concordar que as desigualdades desnecessárias, evitáveis e injustas devem ser combatidas para que as pessoas tenham oportunidade de alcançar o direito ao bem-estar, e isso limitando as liberdades individuais que contribuam efetivamente à persistência de tais desigualdades; porém, a afirmação de que o papel da Promoção da Saúde é provocar transformações radicais nas atitudes e condutas da população e seus dirigentes - supostamente responsáveis por tais calamidades - apresenta-se autoritária se não for seguida de argumentos cogentes que justifiquem tal correlação.

Em 1997, foi emitida a Declaração de Jacarta que, assim como as outras Declarações, trata, além das questões coletivas, também daquelas relativas ao plano privado, fortalecendo, assim, a orientação para a responsabilização do indivíduo pelo cuidado com a própria saúde. Em 1998, a primeira reunião formal da Rede de Megapaíses para a Promoção da Saúde da OMS formou uma aliança entre os países mais populosos (Organização Panamericana da Saúde, 1998), defendendo - como umas das estratégias para fortalecer a capacidade de promoção da saúde global - os estilos de vida saudáveis, sobretudo no que se refere ao tabagismo, nutrição e atividade física.

A Declaração do México, de 2000, reconhece que "a promoção da saúde e do desenvolvimento social é um dever e uma responsabilidade central dos governos, compartilhada por todos os setores da sociedade" (Declaração do México, 2000, p.1). Ainda recomenda, como ação, "assumir um papel de liderança para assegurar a participação ativa de todos os setores e da sociedade civil na implementação das ações de promoção da saúde que fortaleçam e ampliem as parcerias na área da saúde" (Declaração do México, 2000, p.2). Por último, a Carta de Bangkok de 2005 coloca a questão do dever da sociedade em relação à saúde, mas sem deixar claro qual seria este dever, embora afirme, de forma genérica, que todos os setores e âmbitos devam advogar pela saúde com base nos direitos humanos e na solidariedade (Carta de Bangkok, 2005).

\section{Para não concluir}

Apesar de estes documentos poderem ser interpretados de diferentes formas, inclusive em direção ao fortalecimento da liberdade individual, eles podem, também, ser utilizados como instrumento biopolítico das práticas sanitárias que servem de reforço para uma ideologia na qual os indivíduos deixam de ser o objeto de interesse principal para se tornarem apenas instrumentos de interesses econômicos, supostamente coincidentes com o interesse de todos. Outra ambiguidade das estratégias da Promoção da Saúde é a abertura que elas permitem para a restrição de liberdades com relação a certos hábitos individuais que afetam apenas ao indivíduo e que, portanto, não deveriam em princípio ser tratados como questões morais.

Por outro lado, a estimativa dos riscos feita pelos epidemiologistas traz importantes consequências políticas e culturais, uma vez que as políticas sanitárias decorrentes influenciam tanto a maneira como as pessoas levam a vida como a própria concepção de saúde e doença (Forde, 1998). Como afirma Ortega (2004, p.15) "o corpo e o self são modelados pelo olhar censurador do outro que leva à introjeção da retórica do risco. O resultado é a constituição de um indivíduo responsável que orienta suas escolhas comportamentais e estilos de vida para a procura da saúde e do corpo perfeito e o desvio aos riscos". A proposta da Promoção da Saúde de agir no sentido de fortalecer os indivíduos por meio de políticas públicas centradas nos direitos parece estar perdendo força diante do discurso do risco, que tende a relativizá-los e limitá-los em nome de uma suposta necessidade, característica do Estado de Exceção. O principal problema que se coloca é que, quando os governos têm o poder de divulgar dados sobre riscos à saúde, tem-se o perigo de estes serem mal interpretados e, assim, servirem como justificativa para a implementação de medidas coercitivas, ao invés de criarem condições para que as pessoas possam tomar as decisões sobre sua saúde de forma autônoma, inclusive adotando tipos de comportamento de risco que não afetem terceiros, se assim escolherem e de acordo com seus desejos.

De acordo com os aspectos biopolíticos envolvidos, a doença se torna um fenômeno de população e as pessoas passam a substituir seus hábitos, tidos como não saudáveis, por outros, supostamente 
saudáveis; mas, por outro lado, os indivíduos se encontram cada vez mais preocupados com os riscos atrelados ao estilo de vida, se tornando obsessivos pela busca da saúde. Assim, a proposta da Carta de Ottawa de capacitação do indivíduo para o controle sobre a própria saúde se torna algo, de fato, longe de ser alcançado, uma vez que o foco no autocuidado pode acabar tornando o indivíduo refém de uma ideologia healthiest segundo a qual a não realização do objetivo de ser saudável produz ansiedade, angústia e sensação de fracasso, fragilizando o indivíduo; o que acaba, na realidade, por dificultar o controle sobre a própria saúde. Na linha de pensamento do healthism, aqueles que contraem doença são fracos e, portanto, a merecem, reduzindo, assim, a doença a um problema de falta de controle e colocando o indivíduo como "alvo legítimo de repulsa moral e de ostracismo social [sendo que o] sofrimento do outro não é reconhecido; é sua culpa, eles são donos de seu destino" (Ortega, 2003, p.72-3). Esta condenação da vítima, aliada à desresponsabilização do Governo, é algo sobre o qual a bioética deve estar atenta, pois, ao legitimar eticamente os atos humanos que possam ter uma influência significativa irreversível sobre os processos humanos (Kottow, 1995), a bioética se apresenta como uma possível ferramenta para se pensarem os danos provocados pela mudança de paradigma da saúde de um direito para um dever do indivíduo, e se pensarem eventuais formas de resistência a este deslocamento.

Parece claro que a imposição de comportamentos pessoais considerados saudáveis é menos custosa que uma reestruturação das políticas de saúde que garantam uma alocação equitativa dos recursos que seja, ao mesmo tempo, igualitária e libertária, como afirma Berlinguer (2004) em referência à responsabilização histórica dos trabalhadores - e não das empresas - por suas doenças ocupacionais. Porém, devem-se levar em conta problemas como quanto se é livre ou se é socialmente determinado (Castiel, 2004), ou seja, deve-se pensar o que está envolvido no nosso modo de viver, amar, trabalhar, pensar e morrer e, a partir daí, construir políticas de Promoção da Saúde que, efetivamente, estejam preocupadas com a qualidade de vida e o bem-estar das pessoas.

A ideia de autonomia, no contexto da Promoção da Saúde, aparece a partir do conhecimento que as pessoas têm do que é bom e ruim para a saúde, uma vez que, supostamente, podem fazer escolhas e são, portanto, vistas como responsáveis a partir da assimilação do risco e de comportamentos predeterminados. Porém, diferentemente da concepção de liberdade exposta, entendemos que, na realidade, os indivíduos perdem a autonomia, pois se reduz a possibilidade de escolher ser "saudável" ou não. Em suma, a autonomia que ganhamos é "a autonomia para nos vigiarmos, a autonomia e a liberdade de nos tornarmos peritos, experts de nós mesmos, da nossa saúde, do nosso corpo" (Ortega, 2003, p.66).

Pode-se argumentar, de acordo com Mill (1991), que cada um deve ser livre para decidir seu próprio destino, desde que não prejudique terceiros; mesmo que esta escolha seja por um estilo de vida considerado não saudável do ponto de vista sanitário. Assim sendo, no campo da saúde, os comportamentos considerados não saudáveis não devem servir de pretexto para que se apliquem medidas liberticidas. De fato, é plausível afirmar que ninguém é obrigado a ser saudável, embora seja obrigado a não prejudicar a saúde de terceiros.

\section{Colaboradores}

Os autores trabalharam juntos em todas as etapas de produção do manuscrito.

\section{Referências}

AGAMBEN, G. Estado de exceção. São Paulo: Boitempo Editorial, 2004.

AROUCA, S. O dilema preventivista: contribuição para a compreensão e crítica da medicina preventiva. São Paulo: Ed. Unesp, 2003.

BERLINGUER, G. Bioética cotidiana. Brasília: Editora UnB, 2004. 
BUSS, P.M. Promoção da saúde e qualidade de vida. Cienc. Saude Colet., v.5, n.1, p.16377, 2000.

CALIMAN, L. Dominando corpos, conduzindo ações: genealogias do biopoder em Foucault. 2001. Dissertação (Mestrado) - Instituto de Medicina Social, Universidade do Estado do Rio de Janeiro, Rio de Janeiro. 2001.

CALLAHAN, N.D. Setting limits: medical goals in an aging society. Washington: Georgetown University Press, 1987.

CARTA DE BANGKOK, 2005. Disponível em: <http://www.who.int/healthpromotion/ conferences/6gchp/BCHP es.pdf>. Acesso em: 24 jul. 2009

CARTA DE OTTAWA, 1986. Disponível em: <http://<www.opas.org.br/coletiva/ uploadArq/Ottawa.pdf>. Acesso em: 24 jul. 2009.

CARVALHO, S.R. As contradições da promoção à saúde em relação à produção de sujeitos e a mudança social. Cienc. Saude Colet., v.9, n.3, p.669-78, 2004.

CASTIEL, L.D. Promoção de saúde e a sensibilidade epistemológica da categoria 'comunidade'. Rev. Saude Publica, v.38, n.5, p.615-22, 2004.

Dédalo e os dédalos: identidade cultural, subjetividade e os riscos saúde. In: CZERESNIA, D. (Org.). Promoção da saúde: conceitos, reflexões, tendência. Rio de Janeiro: Fiocruz, 2003. p.92.

CILLO, P.F. Oikonomia. In: BRANDIMARTE, R. et al. (Orgs.) Lessico di biopolítica. Roma: Manifesto; 2006. p. 207-11

CRAWFORD, R. You are dangerous to your health: the ideology and politics of victim blaming. Int. J. Health Serv., v.7, n.4, p.663-80, 1997.

Healthism and the medicalization of everyday life. Int. J. Health Serv., v.10, n.3, p.365-88, 1980.

DECLARAÇÃO DE ADELAIDE, 1988. Disponível em: <http://www.opas.org.br/coletiva/ uploadArq/Adelaide.pdf>. Acesso em: 24 jul. 2009.

DECLARAÇÃO DE ALMA-ATA, 1978. Disponível em: <http://www.opas.org.br/coletiva/ uploadArq/Alma-Ata.pdf>. Acesso em: 24 jul. 2009.

DECLARAÇÃO DE SANTAFÉ DE BOGOTÁ, 1992. Disponível em: <http://www.opas.org. br/coletiva/uploadArq/Santafe.pdf>. Acesso em: 24 jul. 2009.

DECLARAÇÃO DE JACARTA, 1997. Disponível em: <http://www.opas.org.br/coletiva/ uploadArq/Jacarta.pdf>. Acesso em: 24 jul. 2009.

DECLARAÇÃO DE SUNDSVALL, 1991. Disponível em: <http://www.opas.org.br/ coletiva/uploadArq/Sundsvall.pdf>. Acesso em: 24 jul. 2009.

DECLARAÇÃO DO MÉXICO, 2000. Disponível em: <http://www.opas.org.br/coletiva/ uploadArq/Mexico.pdf>. Acesso em: 24 jul. 2009

DERNIER, Y. On personal responsibility and the human right to healthcare. Camb. Q. Health Ethics, v.14, p.224-34, 2005.

FORDE, O. Is imposing risk awareness cultural imperialism? Soc. Sci. Med., v.47, n. 9, p.1155-9, 1998.

FORTES, P.A.C.; ZOBOLI, E.L.C.P. Bioética e saúde pública: entre o individual e o coletivo. In: (Orgs.). Bioética e saúde pública. São Paulo: Loyola, 2003. p.11-24.

FOUCAULT, M. Em defesa da sociedade. São Paulo: Martins Fontes, 2005. Zahar, 1997

Resumo dos cursos do Collège de France (1970-1982). Rio de Janeiro: Jorge 
HERZLICH, C. Saúde e doença do século XXI: entre a experiência privada e a esfera pública. Physis, v.14, n.2, p.383-94, 2004.

JONAS, H. O princípio responsabilidade: ensaio de uma ética para a civilização tecnológica. Rio de Janeiro: Contraponto, 2006.

KOTTOW, M. Introducción a la bioética. Santiago: Editoral Universitária, 1995.

LALONDE, M. A new perspective on the health of Canadians. Ottawa: Goverment Canadá, 1974.

MILL, J.S. Sobre a liberdade. Petrópolis: Vozes, 1991.

ORGANIZAÇÃO PANAMERICANA DA SAÚDE. Rede de megapaíses, 1998. Disponível em: <http://www.opas.org.br/coletiva/uploadArq/Mgpaises.pdf>. Acesso em: 24 jul. 2009.

ORTEGA, F. The biopolitics of health: reflections on Michel Foucault, Agnes Heller e Hannah Arendt. Interface - Comunic., Saude, Educ, v.8, n.14, p.9-20, 2004.

. Práticas de ascese corporal e constituição de bioidentidades. Cad. Saude Coletiva, v.11, n.1, p.59-77, 2003.

PAIM, J.S.; ALMEIDA, F.N. Saúde coletiva: uma "nova saúde pública" ou campo aberto a novos paradigmas? Rev. Saude Publica, v.32, n.4, p.299-316, 1998.

SCHRAMM, F.R. A saúde é um direito ou um dever? Autocrítica da saúde pública. Rev. Bras. Bioética, v.2, n.2, p.187-200, 2006.

. Bioética da proteção em Saúde Pública. In: FORTES, P.A.C.; ZOBOLI, E.L.C.P.

(Orgs.). Bioética e saúde pública. São Paulo: Loyola, 2003. p.71-84.

A terceira margem da saúde: ética natural, complexidade, crise e responsabilidade no saber-fazer sanitário. Brasília: Editora UnB, 1996.

SEN, A.K. Desenvolvimento como liberdade. São Paulo: Companhia das Letras, 2000.

SOUZA, E.M.; GRUNDY, E. Promoção da saúde, epidemiologia social e capital social: interrelações e perspectivas para a saúde pública. Cad. Saude Publica, v.20, n.5, p.1354-60, 2004.

VAZ, P.; BRUNO, F. Risco e Justiça. In: CALOMENI, T.C.B. (Org.). Michel Foucault: entre o murmúrio e a palavra. Campos: Editora Faculdade de Direito de Campos, 2004. p.101-31.

Um corpo com futuro. In: PACHECO, A.; COCCO, G.; VAZ, P. (Orgs.). O

trabalho da multidão. Rio de Janeiro: Gryphus, 2002. p.121-46.

Do desmascaramento ao descrédito. Lumina - Rev. Fac. Comunic. UFJF, v.2, n.1, p.59-73, 1999.

WIKLER, D. Personal and social responsibility for health. Ethics Int. Affairs, v.16, n.2, p.47-55, 2002.

ŽIŽEK, S.; DALY, G. Arriscar o impossível: conversas com Žižek. São Paulo: Martins Fontes, 2006. 
GAUDENZI, P.; SCHRAMM, F.R. La transición paradigmática de la salud como un deber del ciudadano: una mirada a la salud pública Interface - Comunic., Saude, Educ., v.14, n.33, p.243-55, abr./jun. 2010.

Una de las preocupaciones actuales de la salud pública es el tipo de responsabilidad que podría exigirse legítimamente de los individuos por su salud y, en particular, preguntarse si se justifica moralmente alguna forma de penalización contra los comportamientos considerados no saludables. La bioética aplicada a la moralidad de las acciones en salud pública pretende garantizar tanto un padrón de acceso a un sistema de salud con cobertura universal como el desarrollo de las capacidades humanas; debiendo por tanto afrontar el conflicto entre los principios de la justicia social y de la autonomía individual, ponderando de la protección de la salud de los necesitados y de las libertades fundamentales de todos y de cada uno. Para eso, bioética y salud pública deberán interrogarse sobre los efectos bio-políticos inscritos en las políticas sanitarias, situándose en la encruzijada entre la Era de los Derechos y el Estado de Excepción.

Palabras clave: Bioética. Salud pública. Autonomía. Bio-política. Promoción de la salud. 